References

' Manzke H. Symmetrische hyperphalangie des zweiten fingers durch ein akzessorisches metacarpale. Fortschr Rontgenstr 1966; 105:425-7.

2 Catel W. Differentialdiagnose von krankheitssymptomen bei kindern und jugendlichen. Vol 1, 3rd ed. Stuttgart: Thieme, 1961:218-20.

${ }^{3}$ Sundaram V, Taysi K, Hartmann AF, Shackleford GD, Keating JP. Hyperphalangy and clinodactyly of the index finger with Pierre-Robin anomaly: Catel-Manzke syndrome. A case report and review of the literature. Clin Genet 1982;21:407-10.

${ }^{4}$ Silengo MC, Franceschini P, Cerutti A, Fabris C. Pierre Robin syndrome with hyperphalangism-clinodactylism of the index finger: a possible new palato-digital syndrome. Pediatr Radiol 1977;6:178-80.

5 Gewitz M, Dinwiddie R, Yuille T, Hill E, Carter CO. Cleft palate and accessory metacarpal of index finger syndrome: possible familial occurrence. J Med Genet 1978;15:162-3.
- Stevenson RE, Taylor HA, Burton OM, Hearn HB. A digito-palatal syndrome with associated anomalies of the heart, face, and skeleton. J Med Genet 1980;17:238-41.

${ }^{7}$ Holthusen W. The Pierre Robin syndrome: unusual associated developmental defects. Ann Radiol (Paris) 1972;15:253-62.

${ }^{8}$ Farnsworth PB, Pacik PT. Glossoptotic hypoxia and micrognathia - the Pierre Robin sequence reviewed. Clin Pediatr 1971;10:600-6.

9 Lipson A, Beuhler B, Bartley J, et al. Maternal hyperphenylalaninaemia fetal effects. $J$ Pediatr 1984;104:216-20.

${ }^{10}$ Stevenson RE, Huntley CC. Congenital malformations in offspring of phenylketonuric mothers. Pediatrics 1967;40:33-45.

Correspondence and requests for reprints to Dr E M Thompson, Clinical Genetics Unit, The Hospital for Sick Children, Great Ormond Street, London WC1N 3JH.

\title{
Outcome after prenatal detection of a sporadic, unstable translocation $\mathrm{t}(5 ; 21)$
}

ALICE O MARTIN*, IRWIN BENUCK†, HOWARD S TRAISMAN†, MAURICE S SWANSON , NICKLAS TRAKAS*, KERRY LAING*, BARBARA J ROSINSKY*, JUDITH BEAIRD*, EDWARD S TRAISMAN ${ }^{*}$, SHERMAN ELIAS*, AND JOE LEIGH SIMPSON*

${ }^{*}$ Section of Human Genetics, Department of Obstetrics and Gynecology, Northwestern University Medical School and Northwestern Memorial Hospitals; †Department of Pediatrics, Northwestern University Medical School and Children’s Memorial Hospital, Chicago, Illinois 60611; and $¥$ Department of Biochemistry, Molecular Biology and Cell Biology, Northwestern University, Evanston, Illinois 60201, USA.

SUMmary Amniotic fluid cultures from a 37 year old woman showed a sporadic $46, X X, t(5 ; 21)(5 q$ ter $\rightarrow 5 \mathrm{p} 13$ or $\mathrm{p} 14:: 5 \mathrm{pter} \rightarrow 5 \mathrm{p} 13$ or $\mathrm{p} 14:: 21 \mathrm{p} 12 \rightarrow 21 \mathrm{qter})$ complement. In the majority of metaphases the $5 p$ fragment was attached to the stalks of chromosome 21; however, in $9 \%$ of metaphases, the fragment was loosely attached by a 'thread' and in $6 \%$ it was completely detached. Silver staining and in situ hybridisation with a homologous ribosomal gene probe, which localises to stalk regions (nucleolar organisers, NOR) of human acrocentric chromosomes, failed to show a reciprocal exchange. Prognosis was uncertain because the possibility that the $5 p$ fragment might have been lost in some cell lines could not be excluded. Nonetheless, the parents elected to continue the pregnancy. The translocation was confirmed in blood specimens obtained both at birth and at 1 year of age and

Received for publication 27 July 1985 Accepted for publication 13 August 1985 showed similar instability. However, the proband shows no anomalies and is developing normally at 1 year.

\section{Case report}

The mother was a 37 year old Caucasian female in good health. Her three previous pregnancies resulted in two normal offspring and one first trimester miscarriage. She underwent amniocentesis for prenatal diagnosis at 18 weeks' gestation because of advanced maternal age. Family history was unremarkable except for one paternal uncle of the proband said to be 'slow', and one distant cousin said to have Down syndrome. Records were not available on these two people. Pregnancy had been unremarkable, there were no documented exposures to potential teratogens, and the only drugs taken were iron and vitamins. After the chromosomal aberration (to be described later) was detected in amniotic fluid cultures, detailed ultrasound examinations were performed at 21 and 29 weeks' gestation. There was no evidence of growth retardation or anomalies. Despite the uncertain prognosis, 
in particular because some fetal cells may have lost the $5 p$ fragment, the parents elected to continue the pregnancy. Labour and delivery were uneventful. Apgar scores were 9 at one and five minutes. The female infant weighed $3.63 \mathrm{~kg}$ (90th centile), measured $53.5 \mathrm{~cm}$ in length ( 95 th centile), and had a head circumference of $35 \mathrm{~cm}$ (75th centile). Physical examination revealed no anomalies.

During the first year of life growth and psychomotor development have been completely normal. The proband's only illness was a mild upper respiratory infection at 9 months of age. At her most recent physical examination at 1 year of age she weighed $10 \mathrm{~kg}$ (70th centile), measured $80 \mathrm{~cm}$ in length (95th centile), and had a head circumference of $47 \mathrm{~cm}$ (80th centile).

CYTOGENETIC ANALYSIS

Amniotic fluid cultures were initiated in routine fashion, which in our laboratory includes use of several types of culture media (Chang's, Ham's F12 in this case). Chromosomal analysis of GPG banded preparations two weeks later (pancreatin pretreatment followed by staining in Wright's Giemsa)

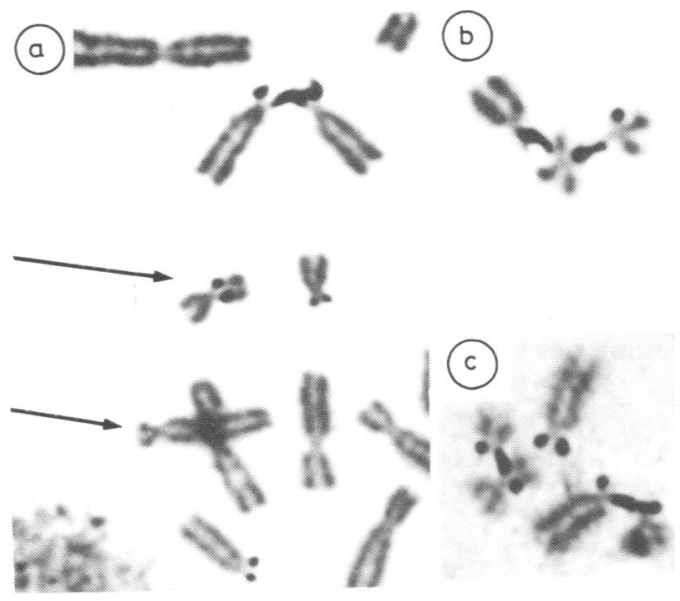

FIG 2 (a) The arrows indicate the appearance of the $\operatorname{der}(21)$ after silver staining and the der(5) which was Ag negative in all cells examined. (b) and (c) Association of der(21) with $D$ and $G$ group chromosomes as revealed by silver staining.

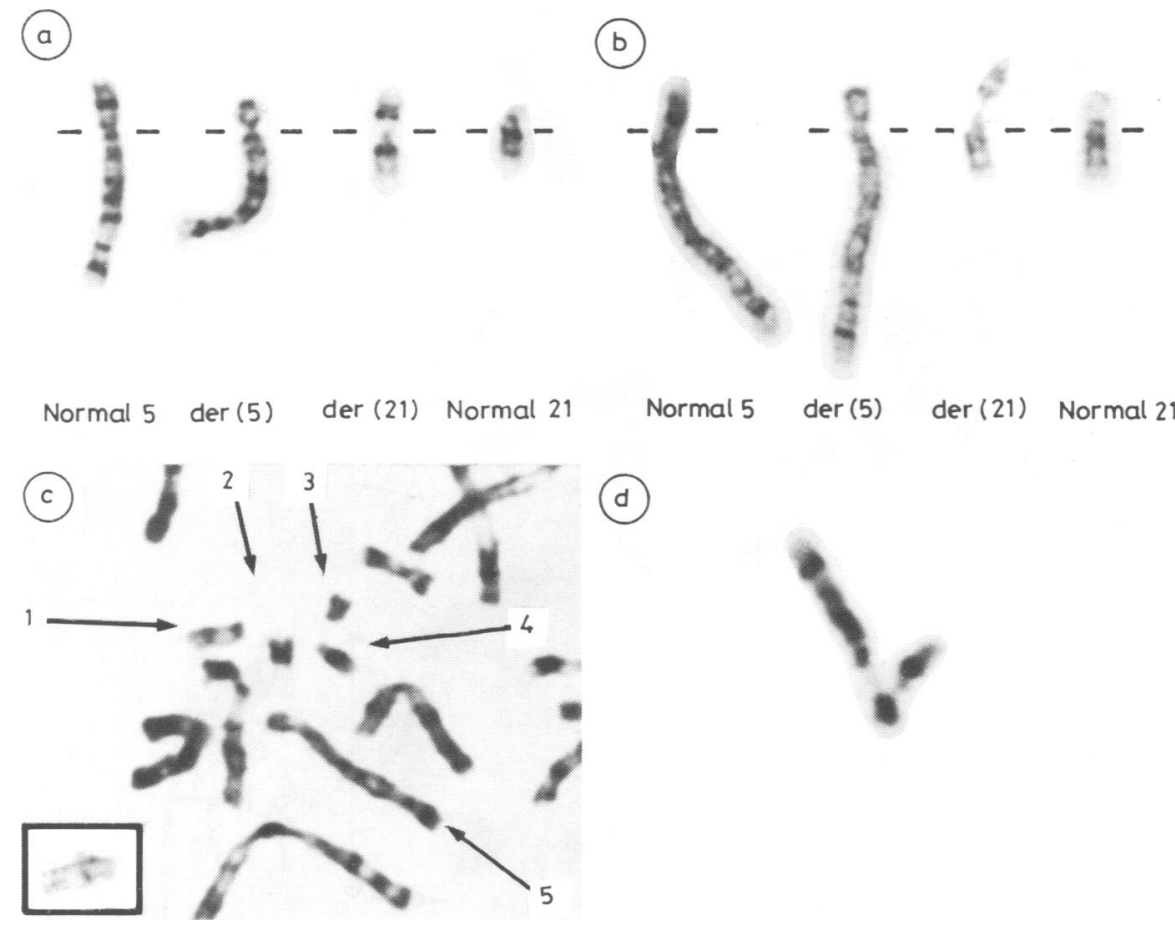

FIG 1 Translocation between $5 p 13$ or p14 and 21 p12 exhibiting morphological instability. (a) The portion from $5 p$ appears firmly attached to $21 \mathrm{p}$. (b) The portion from $5 p$ is loosely attached to $21 \mathrm{p}$. (c) The portion from $5 p$ has become detached from $21 p$. (d) There is an association between der(21) and a chromosome 14. 
revealed an unusual translocation between the stalk region of chromosome 21 and $5 p 13$ or 14 . All 94 cells from three cultures showed the two breakpoints. Usually (79 of 94 cells) the fragment from $5 p$ was observed attached to the stalk region of chromosome 21 (fig 1a). In nine of the remaining 15 metaphases, it was attached loosely by a 'thread' to the stalks (fig 1b) and in six cells the fragment appeared completely detached, that is, appeared as an acentric fragment (fig 1c). The fragment was found in association with chromosome 14 in two metaphases (for example, fig 1d). Analysis of
50 cells from each of the parental peripheral blood cultures revealed no aberrations, nor any obvious 21 heteromorphisms (GPG banding) that would indicate the parental origin of the aberration.

After the infant was born, further studies were initiated. Cytogenetic analysis of 76 metaphases derived from cord blood cultures confirmed the presence of the aberration. In a single cell, however, only 45 chromosomes were present because the der(21) was absent. The morphological heterogeneity (instability) observed was similar to that seen in the cultures derived from amniotic fluid. In

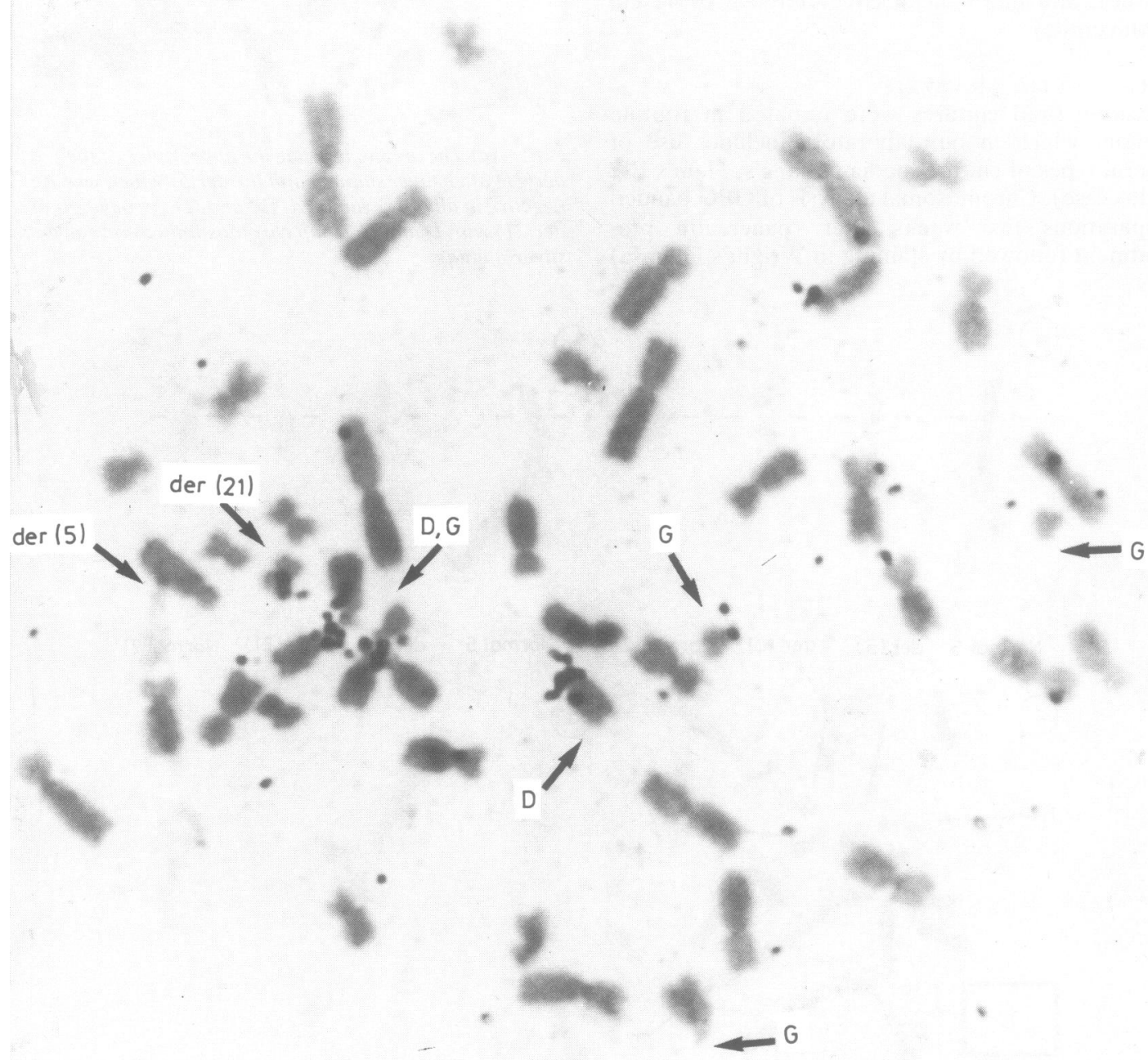

FIG 3 Example of a metaphase after in situ hybridisation with a homologous $28 \mathrm{~S}$ rDNA probe labelled with ${ }^{3} \mathrm{H}$. Arrows indicate the der(5) and der(21). No label was ever observed in the der(5). 
addition, association of the der(21) with a chromosome 15 was observed in one of 76 cells. (RPMI 1640 and Ham's F12 media were used).

Silver staining (a modification of the method of Howell and Black $^{1}$ ) revealed an interstitial $\mathrm{Ag}$ positive region on der(21) (fig 2a). Silver bridges were also observed whenever the $\operatorname{der}(21)$ was associated with D or $\mathrm{G}$ group chromosomes (fig 2b). No positive silver staining of $\operatorname{der}(5)$ was observed in 15 cells exhibiting optimal silver staining, nor was the deleted chromosome 5 observed in association with an acrocentric chromosome (several hundred cells analysed).

In situ hybridisation to chromosomes was also performed using a pBR3 based recombinant plasmid containing $7 \cdot 3 \mathrm{kbp}$ of human genomic DNA, which is comprised of $0.2 \mathrm{kbp}$ of the $3^{\prime}$ end of the $18 \mathrm{~S}$ rDNA, $2.5 \mathrm{kbp}$ of internal transcribed spacer, $5.8 \mathrm{rDNA}$, and $4.6 \mathrm{kbp}$ of the $28 \mathrm{~S}$ rDNA gene. This plasmid was ${ }^{3} \mathrm{H}$ labelled by nick translation. ${ }^{2}{ }^{3}$ Slides were first treated with DNase free RNase $(100 \mu \mathrm{g} / \mathrm{ml})$ in $2 \times \mathrm{SSC} / 1 \mathrm{mmol} / \mathrm{EDTA}$ at $37^{\circ} \mathrm{C}$ for one hour. Following dehydration in a graded ethanol series $(70 \%, 90 \%, 100 \%)$ they were air dried and stored in a dessicator. Chromosomal DNA was denatured at $70^{\circ} \mathrm{C}$ for two minutes in $70 \%$ deionised formamide (FA) $/ 2 \times$ SSC, and the slides were ethanol dehydrated and air dried. Hybridisations were performed using $50 \% \mathrm{FA} / 2 \times \mathrm{SSC} / 10 \%$ (w/v) dextran sulphate, $250 \mu \mathrm{g} / \mathrm{ml}$ denatured and sonicated calf thymus DNA, and $200 \mathrm{ng} / \mathrm{ml}{ }^{3} \mathrm{H}$ plasmid (specific activity of approximately $2 \times 10^{7}$ $\mathrm{cpm} / \mu \mathrm{g}$ ) at $42^{\circ} \mathrm{C}$ for 24 hours in a humidified chamber. Slides were washed $3 \times 3$ minutes in $50 \%$ $\mathrm{FA} / 2 \times \mathrm{SSC} / 42^{\circ} \mathrm{C}$ and $5 \times 2$ minutes in $2 \times \mathrm{SSC} / 42^{\circ} \mathrm{C}$, dehydrated, coated with nuclear track emulsion (Kodak NTB-2), and stored at $4^{\circ} \mathrm{C}$ in a dessicator. Samples were developed at two and three weeks, the latter providing optimal preparations. One hundred cells were scanned which showed definitive labelling of at least some of the acrocentric chromosomes and in which the der(5) could be identified by morphology (fig 3). In no cell was any label observed on der(5). Consequently, we were not able to demonstrate that the $\operatorname{der}(5)$ received a reciprocal exchange from chromosome 21 . Presumably, parts of the stalk and attached satellites distal to the break in $21 \mathrm{p} 12$ were lost.

\section{Discussion}

The chromosomal rearrangement $t(5 ; 21)(5 q$ ter $\rightarrow 5 \mathrm{p} 13$ or p14::5pter $\rightarrow 5 \mathrm{p} 13$ or $\mathrm{p} 14:: 21 \mathrm{p} 12 \rightarrow 21 \mathrm{qter})$ detected initially in amniotic fluid cultures has several unusual features. One breakpoint was in the stalk of an acrocentric chromosome, creating an unstable attachment of a fragment of $5 \mathrm{p}$. This instability was presumably due to the interstitial NOR (stalk). Translocations of NORs appear to be rare events, ${ }^{4-7}$ indicating either that breaks are infrequent in stalks, or that if they occur, the result is unstable and consequently not detected. Indeed, stalks are not usually preserved in the relatively common Robertsonian translocations. ${ }^{8-12}$ We are not aware of any previous reports of a morphologically unstable, acentric fragment with an attached stalk. Although the detachment of the $5 p$ was occasionally observed, producing an unstable fragment, the piece was never lost. The in vitro observations may not reflect the in vivo situation, where the attachment could be either more or less stable.

A reciprocal exchange was not demonstrated; the broken end of $5 p$ was presumably converted to a telomere, assuring a functionally stable chromosome configuration. Regeneration of telomeres is possible under the model that the composition of telomeres are repeats of $5^{\prime} \mathrm{C}_{1-3} \mathrm{~A} 3^{1} .{ }^{13}$

Because of our concern that loss of the $5 p$ fragment might occur in vivo, a normal phenotypic outcome could not be guaranteed to the parents. However, they decided to continue the pregnancy. Fortunately, the proband appears phenotypically normal; however, problems would be anticipated in her own future reproduction. Because we were not able to demonstrate a reciprocal exchange, and because only the $5 p$ region could form a link between the chromosomes 5 and 21, pairing may be predominantly independent. If that were the case, $50 \%$ of the gametes would have the $5 p$ region either deleted or in triplicate, both complements compatible with a viable, abnormal offspring. If the $5 p$ do indeed pair, the same type of unbalanced gametes would be expected from adjacent 1 segregation as from independent segregation. Although this is not a reciprocal translocation, the most likely segregation, based on criteria proposed by Jalbert and colleagues, ${ }^{14}$ seems to be adjacent 1 and $3: 1$. This prediction is based on the observations that (1) translocated and non-translocated segments are of unequal length; (2) an acrocentric is involved; (3) non-translocated segments are long relative to the translocated one; and (4) the translocated 'segments' are of unequal length (actually one is of 'zero' length because reciprocal exchange could not be demonstrated).

The frequency of unbalanced gametes might even be higher than predicted from expected segregation ratios, because the instability observed in vitro might occur during meiosis, causing potentially balanced gametes to be del(5p). Prenatal diagnosis would be recommended when the proband reaches reproductive age. Although her phenotype appears 
normal, it seems that only the normal gamete with no derivative chromosome could safely be predicted to be normal phenotypically. The occurrence of a normal gamete would be at most $25 \%$.

\section{References}

' Howell WM, Black DA. Controlled silver staining of nucleolus organizer regions with a protective colloidal developer: a onestep method. Experientia 1980;36:1014-5.

2 Erickson JM, Rushford CL, Darney DJ, Wilson GN, Schmickel RD. Structure and variation of human ribosomal DNA: molecular analysis of cloned fragments. Gene 1981;16:1-9.

${ }^{3}$ Maniatis T, Jeffrey A, Kleid DG. Nucleotide sequence of the rightward operator of phage. Proc Natl Acad Sci USA 1975:72:1184-8.

4 Varley JM, Gosden J, Hultén M. Familial reciprocal translocation $\mathrm{t}(9 ; 13)(\mathrm{p} 11 ; \mathrm{p} 12)$ investigated by silver staining and in situ hybridisation. Hum Genet 1981;59:422-8.

5 Watt JL, Couzin DA, Lloyd DJ, Stephen GS, McKay E. A familial insertion involving an active nucleolar organiser within chromosome 12. J Med Genet 1984;21:379-83.

' Hansmann I, Wiedeking C, Grumin T, Gebauer J. Reciprocal and nonreciprocal chromosome translocations. Hum Genet 1977;38:1-5.

' Dev VG, Byrne J, Bunch G. Partial translocation of NOR and its activity in a balanced carrier and in her cri-du-chat foetus. Hum Genet 1970;51:277-80.
${ }^{8}$ Brasch JM, Smyth DR. Absence of silver bands in human Robertsonian translocation chromosomes. Cytogenet Cell Genet 1979;24:122-5.

9 Mattei MG, Mattei JF, Amymedel S, Giraud F. Dicentric Robertsonian translocation in man: 17 cases studied by R, C and $\mathrm{N}$ banding. Hum Genet 1979;50:33-8.

10 Gamberg N, Pajunen L, de la Chapelle A. NOR activity in two families with balanced $D ; D$ translocations and numerous consecutive miscarriages. Hereditas 1980;92:217-21.

" Mikkelsen M, Rasli A, Paulsen H. Nucleolar organizer regions in translocations involving acrocentric chromosomes. Cytogenet Cell Genet 1980;26:14-21.

12 Gosden JR, Lawrie SS, Gosden CM. Satellite DNA sequences in the human acrocentric chromosomes: information from translocations and heteromorphisms. Am J Hum Genet $1981 ; 33: 243-51$.

${ }^{13}$ Szostak JW, Blackburn EH. Cloning yeast telomeres on linear plasmid vectors. Cell 1982;29:244-5.

14 Jalbert P, Sele B, Jalberg H. Reciprocal translocations: a way to predict the mode of imbalanced segregation by pachytenediagram drawing. A study of 151 human translocations. Hum Genet 1980;55:209-22.

Correspondence and requests for reprints to $\mathrm{Dr} \mathrm{A} \mathrm{O}$ Martin, Laboratory of Cytogenetics, Northwestern University Medical School, Prentice 1176, 333 E Superior, Chicago, Illinois 60611, USA. 